\title{
Determining the Difficulty Level of Listening Tasks
}

\author{
Zohre Mohamadi \\ English Teaching Department, Islamic Azad University of Karaj, Karaj, Iran
}

\begin{abstract}
Materials development has distinguished history but this history is exclusively devoted to designing, developing and sequencing language activities. Assessing difficulty level of activities is an integral part of this process whose history is exclusively devoted to reading, writing, and speaking skills. This research aimed at introducing significant elements that trigger potential sources of difficulty for language learners. Since listening skill is the Cinderella skill (neglected by discourse community in comparison with other skills) especially at Asian context, and since difficulty level of tasks has been scientifically proved to have significant effects on language learning and more generally in motivating and demotivating the learners, this research can provide insights for language teachers and learners by helping them to notice how language activities and their inherent features may facilitate or hinder language learning.
\end{abstract}

Index Terms - learning, teaching, listening tasks, difficulty level, materials development, and syllabus design

\section{INTRODUCTION}

Determining difficulty levels of tasks has been one of the distinguishing factors that affect language learning candidates. A number of factors that appear to influence task performance in the classroom have been identified (although these have differed to some extent among researchers). Robinson, (2001) examined a number of factors that interact with each other so they are considered as key variables in the design of the listening tasks. These factors include the text itself, other components of the tasks and attributes of individual.

The problem with this study is that the difficulty factors were identified post hoc rather than as a pre-existing taxonomy or framework as is the case with the current study. Robinson (2001) identified two set of influential factors in complexity of tasks. These are "resource-directing" factors (e.g., number of task elements, reasoning demands of the task, immediacy of information provided) and "resource-depleting" factors (e.g., planning time, number of tasks, prior knowledge) (Robinson, 2001, p. 30). Robinson claims variations in the quality of language produced by the learners are due to the manipulation in the factors as this manipulation requires varying cognitive demands (e.g., amount of attention, memory, reasoning and other information processing). Skehan (1996) proposed which has three different factors;

- Code complexity: incorporating both linguistic complexity/variety and vocabulary load/variety;

- Cognitive complexity: involving cognitive processing factors such as information type and organizational structure as well as the familiarity of task topic discourse and genre; and

- Communicative stress: referring to the logistics of task performance e.g., time pressure, nature of the prompt and number of participants.

Skehan and Foster (1999) have proposed that more complex tasks divert learners' attention from form to context. Simple task create more fluent and more accurate speech, whereas more complex tasks create more complex speech at the expense of accuracy and fluency.

Another factor which is open to research is individual attributes such as anxiety, confidence and motivation - which produce different levels of stress and engagement during task performance. These factors interact with the characteristics in a complex way (Robinson, 2001). Accordingly, following previous work on tasks, Robinson (2001) proposes a distinction between complexity and difficulty suggesting that complexity is a feature of task and difficulty as perceptions of task difficulty on the part of learners. Of relevance to the present study is research comparing task-taker reactions to different task types. This shows that task-takers prefer for certain types of tasks as they are perceived to be easier, more interesting or more acceptable as measures of ability than others.

The results of the study of semi-direct oral tasks mentioned in the research are interesting. The result shows that that test-takers consider this format more difficult and/or more stressful than the live interview situation. Preparation time is perceived as a factor in test difficulty in the tape-based format. It is believed that providing greater preparation time in pre-task planning stage on a tape-based oral test will reduce stress and the perceived difficulty level.

Brown (1986) reported other difficulty factors including inadequate response time, unfamiliar vocabulary, speed of voices on the tape, lack of clarity in instructions, unclear prompts, too much input material to process and lack of familiarity with the task type. Whereas tasks features that lead to more difficulty level can be revised, the control for the attributes of the candidate is difficult.

\section{LISTENING TASKS}


One problem with outcome-based systems is threats to validity and reliability issues which may lead to invalid inferences about learners' achievement of the target outcome. By the study of task comparability, Brindley and Slatyer (2002) focused on variations on task condition and task characteristics which influence difficulty of listening tasks.

TABLE 1

COMPETENCY DESCRIPTION (BRINDLEY \& SLATYER, 2002)

\begin{tabular}{|c|c|c|c|}
\hline Elements & Performance Criteria & Range statement & Evidence guide \\
\hline $\begin{array}{l}\text { I. can identify main ideas } \\
\text { II. can identify explicitly } \\
\text { stated information } \\
\text { III. can identify supporting } \\
\text { arguments } \\
\text { IV. can identify implicit } \\
\text { ideas/information } \\
\text { V. can identify logical } \\
\text { relationships } \\
\text { VI can demonstrate } \\
\text { understanding of } \\
\text { vocabulary }\end{array}$ & $\begin{array}{l}\text {-Identifies main ideas } \\
\text { - identifies specific } \\
\text { information which } \\
\text { Supports or elaborates on } \\
\text { main } \\
\text { Ideas }\end{array}$ & $\begin{array}{l}\text { - Familiar and relevant } \\
\text { topic } \\
\text { - text segment for } \\
\text { assessment approximately } \\
2 \text { minutes in length } \\
\text { - fluent speaker } \\
\text { (excluding classroom } \\
\text { teacher) } \\
\text { - live speaker/ TV (On- } \\
\text { line or video)/ radio or } \\
\text { cassette } \\
\text { - single listening only } \\
\text { - questions should be } \\
\text { given to learners before } \\
\text { they listen } \\
\text { - written responses need } \\
\text { not be grammatically } \\
\text { correct or in sentence form } \\
\text { but errors should not } \\
\text { interfere with meaning } \\
\text { - multiple choice should } \\
\text { not be used }\end{array}$ & $\begin{array}{l}\text { Sample tasks: learners } \\
\text { listen to and answer } \\
\text { questions on a short } \\
\text { lecture/ classroom } \\
\text { presentation } \\
\text { - speaker from local } \\
\text { employment agency } \\
\text { - speaker from job } \\
\text { training program } \\
\text { - talk at education center } \\
\text { - speaker from union/ } \\
\text { professional organization }\end{array}$ \\
\hline
\end{tabular}

To assess the same competency there is a need to use the tasks that elicit the same behaviors and implemented in the same ways. To achieve this, the tasks need to have the same degree and type of contextual support and present a comparable level of cognitive challenge for learners. Secondly, assessors need to classify the competencies in a consistent way. This requires a common interpretation and application of the performance criteria within each competency.

Results of the studies show that reaching high consistency in categorization is difficult in real life situations and noticeable variations are inevitable in the way that the tasks are designed, administered and rated.

Most of bulks of the research in this regard have been devoted to find the extent to which variations in tasks characteristics and conditions may influence learners' language output. Wigglesworth (2000 cited in Uso'-Juan \& Martı'nez-Florn, 2006) reported that leaners' language behaviors change both qualitatively and quantitatively. In order to design valid competency assessment tasks, researchers need to control for the task effects.

The research studies displayed factors that affect variations in tasks and the design of writing and speaking tasks. However, whether the same factors result in the same degree of variation in receptive competencies is open to research. The principal aim of the present study is to identify key task characteristics and task conditions that were most likely to affect the difficulty of listening tasks.

\section{FACTORS AFFECTING TASK DifFICULTY}

It is axiomatic that listening is the primary vehicle by which a person acquires an L2. Listening opportunities "provide the linguistic environment" or "set the stage" for acquisition. What must be acquired in L2 acquisition is a range of new knowledge and a multi-faceted set of skills for using this knowledge:

1. A new perceptual mode for categorizing the phonological system of the L2

2. An abstract system of novel grammatical rules

3. A lexical system that is linked to the semantic system of the first language (L1) (Nation (2001) cited in Uso'-Juan \& Martı'nez-Florn, 2006)

4. A comparative pragmatic system

5. A set of language specific processing procedures

6. A set of complex cognitive skills that allow for "thinking in the L2"

All of these types of knowledge and opportunities for skill development are available to the learner through listening input, but acquisition is not automatically brought about by mere exposure to the input. The learner, in order to acquire the L2, must come to understand input in personally meaningful ways, engage in interactions and tasks based on that input, and simultaneously pay attention to the form of the input and interaction that will allow for permanent development of L2 knowledge and skills. We know that significant development in an L2 requires a great quantity of listening - certainly on the order of hundreds of hours per year. What is less clear is how the type and quality of input 
affects learner engagement and eventual acquisition from the input. Factors that affect quality of input include relevance, difficulty, and authenticity.

A large number of factors that may affect listening task difficulty have been identified by researchers; amongst these are:

A. The Nature of the Input:

Nature of the input includes speech rate, length of passage, syntactic complexity, vocabulary, discourse structure, noise level, accent, register, propositional density, amount of redundancy, etc.;

1. Accessibility of input. Access to relevant and appropriately challenging input is a critical factor in listening development.

2. Relevance. Relevance refers to the personal significance of the input. As Beebe (1988 cited in Uso'-Juan \& Martı'nez-Florn 2006) aptly describes, unless individual learners find "the right stuff" - listening and reading input - to fuel their intrinsic motivation for acquisition, it is unlikely that they will become sufficiently engaged to trigger the mental processes needed for sustained development. Because of its subjective nature, relevance can only be measured in terms of sustained effort to understand. The more relevant the listening opportunities, the more motivated the learner is likely to be to continue seeking comprehensible input.

3. Difficulty. Difficulty refers to the intrinsic "cognitive load" of a listening or reading text, its linguistic and informational complexity. Text difficulty is a reflection of the cognitive processes required for an adequate understanding of a text and is known to include several variables involving length, speed, familiarity, information density, and text organization (Table 2)

TABLE 2:

TEXT DIFFICULTY (BASED ON ROST (2002) CITED IN USO'-JUAN \& MARTI’NEZ-FLORN, 2006)

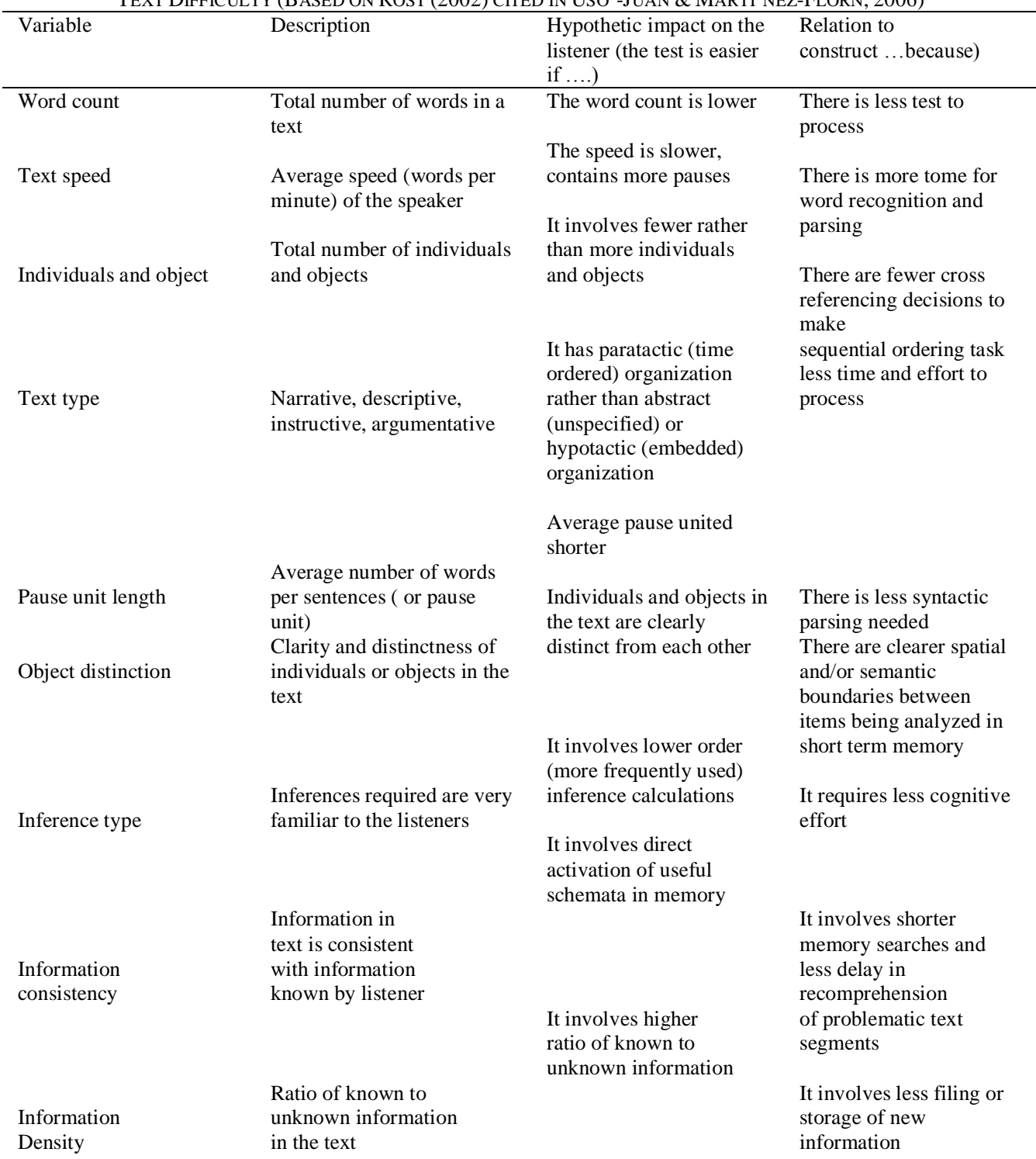


4. Authenticity. Authenticity refers to the degree to which a text is a legitimate sample of the way the language is actually used. This notion is important because we can only acquire a target language by drawing inferences and making generalizations from valid samples. In language pedagogy, authenticity has been approached in different ways. It is sometimes believed that mere exposure to genuine texts (i.e., listening texts used by native speakers in an "authentic" context) are helpful for learning to listen. Long (1996 cited in Uso'-Juan \& Mart1'nez-Florn, 2006), however, claims that genuine texts (except when used at very advanced levels) hamper learning by confronting the learner with large amounts of unfamiliar language (new vocabulary, complex syntax, novel collocations) without compensatory devices to facilitate comprehension. In short, they present too dense a linguistic package for learning purposes. As an alternative to listening to genuine texts, it is often assumed that controlling difficulty through means of text simplification is an aid to both comprehension and eventual development of listening ability. However, this contention has also been called in question. Simplification does not always help comprehension, often because it serves to remove useful redundancy in texts, e.g., by deleting explicit intra- and inter-utterance markers of logical relationships among referents and propositions. Even when simplified texts do improve comprehension, they tend to be stilted, lacking complete cross references (which are needed for normal kinds of logical inference) and intertextuality (cultural references which are necessary for activation of appropriate schemata). In spite of the good intentions by teachers who use them, simplified texts may actually impede learning by modeling unnatural usage: simplified texts remove from the input the very items which learners need to be exposed to in order to eventually acquire the L2.

Two alternatives have been proposed to deal with the genuine vs. simplified text conundrum. One alternative that has been proposed is the use of "elaboration" rather than simplification. Research has shown that elaborated texts are able to bring about almost as great an increase in comprehension as simplified ones, but they achieve this without damaging the richness of the original text (Long (1996) cited in Uso'-Juan \& Marti'nez-Florn, 2006). Comprehension is improved through adding redundancy (various types of natural repetition, amplification and paraphrase) and transparency (overt signaling to increase topic saliency, matching order of mention in the text to the chronological sequence of events, prevalent use of a here-and-now orientation). Another essential feature of elaborated texts is a slower rate of delivery (usually through increasing the length of natural pauses), and where discourse is interactional, by frequent use of clarification requests, comprehension checks and confirmation checks. Because acquisition requires uptake (i.e., longterm retention) of previously unknown linguistic targets (new vocabulary, syntax and collocations), elaboration better assures that learners will notice new items, while they are working to comprehend the text. Another alternative of course is the use of focused processing tasks that provide scaffolding to allow learners to deal with selected aspects of an authentic text. Tasks can include pre-listening steps that provide advance organizers for content and selected vocabulary and concept support to "prime" listeners for "difficult content" that would normally be beyond their comprehension capacity.

5. Frequency effect. Investigating the effect of input features have been at center of attention in SLA. Early research (Gass \& Mackey, 2002) reported a relation between input frequency and learning. For example, Bardovi-Harlig (1987 cited in Gass \& Mackey, 2002) claimed that input frequency can ease the difficulty of learning marked features, and Gass and Lakshmanan (1991 cited in Gass \& Mackey, 2002) found a correlation between (ungrammatical) input and output data.

Nick Ellis's research (cited in Gass, 2002) shows frequency effects. He displayed that frequency is an important cognitive mechanism in every aspect of language processing: phonology, phonotactics, reading, spelling, lexis, morphosyntax, pragmatics, sentence production, and comprehension. Ellis's comprehensive article suggests ways in which work on frequency may link relatively disparate areas and providing a clearer articulation of the construct (Gass, 2002).

6. Input source (live vs. audio-recorded). 'Live' (i.e., text spoken by the teacher or an invited presenter), videorecorded and audio-recorded sources are used in teaching and learning fields. But, these presentation modes are different in terms of contextualization, discourse structure and propositional density and therefore affect leaner performance.

7. Speech rate. Speech rate: many pieces of research have shown that faster speed can reduce comprehensibility in listening tasks.

8. Pausing. One way to make speech directed to learner more comprehensible is that the teachers make more processing time by making pauses. Also, Chaudron and Richards (1986 cited in Leeser, 2004) noted the frequency and length of pauses increase when native speakers talk with non- native speakers and help them to segment discourse into meaningful units by providing more processing time. Blau (1990 cited in Leeser 2004) found that by providing 3second pauses at phrases, sentences and clauses, beginner learners outperformed in their answers to wh- question in comparison with those who were not provided with the pauses. Sagarra (1998 cited in Leeser, 2004), however, did not find significant performance differences on L1 recall tasks between L2 beginning Spanish learners who encountered 1or 2-second pauses inserted at phrase boundaries and 3-second pauses inserted between paragraphs and those that did not. Chaudron and Richards ( 1990 cited in Leeser, 2004) failed to find a significant difference between cloze recall scores for lower and higher proficiency English as a second language (ESL) learners who either listened to a lecture containing discourse markers intersentential relations, framing of segments, and pause fillers (or a baseline lecture) The authors hypothesized that he original listening input was slow enough that additional segmenting, slowing down, or 
pausing may not have contributed to greater comprehension. Similarly, Griffiths (1990 cited in Leeser 2004) reported pauses did not have any effects on comprehension of by intermediate students when the rate was below $150 \mathrm{wpm}$.

9. Text type. Research also suggest that the degree or orality which is the extent to which the input has spoken features rather than written features affect comprehensibility with input containing negotiated discourse more comprehensible

10. Topic familiarity. According to schema-based models, one of the comprehension facilitator factors is learners' background knowledge. These models suggest that prestored schemata or scripts direct comprehension topdown whereas more recent models propose that background knowledge is stored as an associative network of propositions that are activated bottom-up through interaction with the textual data (Nassaji (2002) cited in Leeser 2004). Comprehension depends on the reader or listeners' background knowledge and the familiarity of learners with the scenarios in the task input.

11. Mode. Leow (1995 cited in Leeser 2004) claims there is a need for more research in the area of mode which can provide insight into the selection of the input and increase teacher awareness with what learners do with the input that is made available to them. The L2 studies that have investigated mode have found that readers comprehend more informational content than listeners and that they are better able to allocate attentional resources simultaneously to content and grammatical form. Furthermore, Leow (1995 cited in Leeser 2004) found that L2 Spanish learners who read passages recognized more present perfect and present subjunctive forms than those who listened to the same passages. The researchers all attributed their findings to the hypothesis that processing resources are less constrained in the written mode than in the aural mode.

\section{B. The Nature of the Assessment Task}

The amount of context provided, clarity of instructions, response format, availability of question preview, etc. are factors determine the nature of assessment tasks.

1. Item format. Differing processing required by different item formats affect candidates' performance in listening tests. A study by Berne (1993 cited in Brindley \& Slatyer, 2002) showed participants outperformed in multiple choice questions than on either open-ended or cloze tests, meaning that items requiring only recognition are easier than those requiring retrieval and production. The effect of multiple-choice items was fully explored whereas the effect of short answer and information transfer tasks is still open to research.

2. Context. One of the earliest and most well cited accounts of context's relationship to linguistic knowledge is Hymes (1962, 1974 cited in Collentine \& Freed, 2004). He highlighted eight factors that establish a context for interpersonal communication: setting, participants, end (or purpose), act sequence (form and content of an utterance), key (verbal and nonverbal manner), instrumentalities (choice of channel and code, norms of interaction and interpretation, and genre. Developmental differences have been predicted to occur as a function of the context of learning even by those focusing on the development of cognitive accounts of SLA.

Piske et al. (2001cited in Díaz-Campos, 2004) analyzed factors affecting the degree of foreign accent in the L2 Specifically, they examined the age of L2 learning, length of residence in an L2-speaking country, gender, formal instruction, motivation, language learning aptitude, and amount of L1 use in a group of 90 Italian NSs living in Canada. Their findings indicated that age of L2 learning and frequencies of L1 use are significant predictors of degree of foreign accent. Piske et al. (2001cited in Díaz-Campos, 2004) found that late bilinguals showed stronger foreign accent than early bilinguals and that speakers using their L1 more frequently also showed a stronger degree of foreign accent.

3. Number of hearings. Some tests allow for more than one hearing whereas others do not let. Skehan (1996) suggests participants boast up their listening scores when they hear more than once. The explanation is that when you hear once the task would be more difficult as it increases cognitive load and creates greater demand for online processing the cognitive load by making greater demands for online processing, thereby making a task more difficult. Considering the proficiency level of the students, teachers should concern about the number of hearing.

\section{Listening Instruction}

Listening instruction covers a wide range of teaching strategies. We can define listening instruction as a pedagogic plan that focuses on any of four goals: 1) improving learners' comprehension of spoken language, 2) increasing the quality of learners' intake from spoken input, 3) developing learners' strategies for better understanding of spoken discourse, or 4) engendering a more active participation in face-to-face communication. As such, listening instruction can take place any time spoken language is used, not just during a specific phase of pedagogy involving recorded input and explicitly called "listening practice." There has been in the last several years an evolution in the teaching of listening. The progress is due in part to developments in general communicative language learning methodologies and to advances in technologies that allow for improved access to a wide range of spoken language from multimedia sources. But what has also spurred this evolution is a better understanding of research into the nature of oral communication and into the internal perceptual and comprehension processes of the listener.

1. Teaching reduced forms. Brown \& Hilferty (1986) suggest that there is a correlation between the frequency and variety of ESL students' contractions and their proficiency in ESL. A study (Brown, 1986) of the language of six ESL students provides data that indicate that 1) contraction frequency correlates with general proficiency in English as 
measured by CELT. 2) that more advanced students reduce vowels more frequently that the less advanced, and, 3) that more advanced students contract with a greater number of preceding words. Although the individual students' contraction patterns are idiosyncratic, there do seem to be evolutionary states related to levels of proficiency. They see evidence that the perception and use of reduced forms are crucial to aural comprehension and general ESL proficiency and end their article a call for clear attention to contractions.

2. Strategy instruction. A second source of research has been formalized under the banner of "strategy instruction," in which researchers attempt to isolate approaches, decisions, and tactics that are associated with "successful" (symmetrical, low-anxiety, positive affect) listening. Early researchers of learning strategies began by listing the range of strategies that learners reported using in their attempts at learning a L2. The essential pedagogic implication behind this initial research was that assisting learners in planning and monitoring their attempts at learning would be a benefit, helping them maximize the results of their learning efforts. This type of strategy instruction taps into a basic theme of most motivation theories, namely that intrinsic, self-guided motivation leads to increased time on task and concomitant success, which in turn strengthens motivation. One aspect of this method of compilation research that is misleading, however, is the implication that all instances compiled are necessarily effective for all learners.

Subsequent work on strategy development has focused more on defining a smaller subset of strategies that are consistently associated with successful listening and with more efficient progress in gaining listening skills. Collectively, using introspection and retrospection methodologies, and coupled with measures of actual effects of strategy use on comprehension and retention, this work has identified specific tactics that listeners use to plan, monitor, and modify their listening efforts. The five strategies that are most commonly identified as "successful" are: 1) predicting speaker intentions and activating ideas, 2) monitoring one's own comprehension, 3) asking for clarification (with increasingly focused informational requests), 4) making inferences from incomplete information, and 5) providing personal responses about content (Rost (2002) cited in Uso'-Juan \& Martı'nez-Florn, 2006). By identifying "successful listening strategies" and structuring opportunities for students to practice these strategies, instructors can provide a "laboratory" for L2 learners to experiment with different approaches to use when listening.

\section{The Individual Listener Factors}

Individual listener factors include memory, interest, background knowledge, motivation, etc.

1. Listener status. The listener's perceived status influences comprehension, participation, and value of input for language acquisition. Engagement by the L2 user -assumption of an "active listening" role -promotes acquisition of listening skills and strategies.

In all listening settings, including non-collaborative ones such as listening to an academic lecture or watching a film in a theater, the listener adopts a role along a continuum of participation rights and responsibilities. The assumption of a role affects not only overt participation behaviors, but also the way in which the listener comprehends the event and retains information.

This view of listening roles enables explicit development of attitudes, perspectives and responses that promote more symmetrical participation and more active involvement in the construction of meaning. The extent to which listeners choose to become involved in various discourse situations depends in large part on how they perceive their status in relation to the primary speaker and in relation to the content the speaker is conveying. One known aspect of affective involvement in any discourse setting is the raising or lowering of anxiety and self-confidence, and thus the motivation to participate actively. For non-interactive settings, this involvement may entail the use of higher order cognitive strategies, such as evaluating the speaker's position or taking notes of key points. For interactive settings, this motivation will also involve using higher risk social strategies, such as showing openness and revealing private aspects of self.

It is now known that higher affective involvement promotes enhanced understanding through better connection with the speaker and through construction of more tangible references for remembering the discourse, while lower affective involvement typically results in less connection, less understanding, and minimal efforts to evaluate and repair any misunderstandings that arise. For example, in separate studies Yang (1993 cited in Uso'-Juan \& Mart1'nez-Florn, 2006) and Aniero (1990 cited in Uso'-Juan \& Martı'nez-Florn, 2006) found a clear negative correlation between learners' levels of anxiety (or "receiver apprehension"), their perceived distance from the speaker, and their listening comprehension performance. One well-known effect of perceived social distance is a reduction in the amount of negotiation for meaning — that is, the work that the listener will do to resolve communication difficulties. A related factor in social distance and listening performance is uncertainty. Uncertainty regarding one's role or a likely "map" for the way the discourse is unfolding leads to a decrease in the listener uptaking of turn opportunities, including back channeling. Back channeling signals - or "vocalizations of understanding" as Gardner $(1998,2003)$ calls them - are a primary influence on the speaker's perception of the listener's stance. When the listener does not provide back channeling signals, or does not provide them in the expected fashion (particularly in ritual encounters such as job interviews), the speaker often unconsciously assumes antagonism or indifference. As listener uncertainty increases, the asymmetry of the discourse increases also. As has been well documented, in many stereotypical NS-NNS encounters in which asymmetry develops, the NS quickly assumes a "superiority position," and makes little effort to establish 
"common ground" with the NNS. This often leads to poor mutual affect, strained communication, and misunderstandings which are hard to trace to a single moment in the interaction.

Because asymmetry, anxiety and negative affect among L2 listeners are so pervasive, addressing the listener's role in collaborative discourse has become a vital aspect of listening instruction. There are two important sources of research that contribute to this aspect of instruction. The first source is analysis of the critical problems that L2 participants encounter in discourse: misunderstandings, asymmetrical control, and lack of establishment of common ground. Based on a discourse analysis of these problems (an analysis of organization, symmetry, turn-taking, intention, response, etc.) in real interaction, researchers provide insights into the kinds of problem-solving decisions and techniques that can be used to repair or avoid problems in discourse. Various typologies of listener strategies have been developed to encapsulate these insights (Bremer et al. (1996) cited in Uso'-Juan \& Martı'nez-Florn, 2006) (A general summary is provided in Table 3).

TABLE 3

STRATEGIES OF UNSUCCESSFUL VS. SUCCESSFUL LISTENERS IN INTERACTIVE SETTINGS (BASED ON BREMER ET AL. (1996) CITED IN USO’-JUAN \& MARTÍNEZ-FLORN, 2006)

\begin{tabular}{|c|c|}
\hline $\begin{array}{l}\text { Characteristics of unsuccessful /asymmetrical/passive } \\
\text { listening }\end{array}$ & Characteristics of successful /symm \\
\hline $\begin{array}{l}\text { - waiting for information to "register" } \\
\text { (assuming that the speaker has the } \\
\text { primary role in creating meaning). }\end{array}$ & $\begin{array}{l}\text { - taking a lead in constructing } \\
\text { meaning }\end{array}$ \\
\hline $\begin{array}{l}\text { - assuming the listener is responsible } \\
\text { for any communication failures }\end{array}$ & $\begin{array}{l}\text { - assuming the speaker is (partly) } \\
\text { responsible for any communication } \\
\text { failures }\end{array}$ \\
\hline $\begin{array}{l}\text { not activating background knowledge- } \\
\text { or assumptions (assuming that } \\
\text { speaker will provide all information } \\
\text { necessary for comprehension) }\end{array}$ & $\begin{array}{l}\text { - activating background knowledge } \\
\text { and assumptions to fill in missing } \\
\text { information }\end{array}$ \\
\hline $\begin{array}{l}\text { - not asking for clarification if confusion } \\
\text { arises } \\
\text { - not responding to speaker voluntarily } \\
\text { (not revealing any personal reaction }\end{array}$ & $\begin{array}{l}\text { - asking for clarification when } \\
\text { confusion arises } \\
\text { - providing reactions and responses } \\
\text { to the speaker voluntarily }\end{array}$ \\
\hline
\end{tabular}

\section{CONCLUDING REMARKS}

Buck (1994: 164 cited in Brindley \& Slatyer) suggests, 'performance on each task is a unique cognitive event', then task design will require not only a much more detailed specification of task characteristics and conditions (Bachman and Palmer, 1996), but also it will need to be based on a much better understanding of the interactions between text, task and learner variables. To this end, a good deal of further work will need to go into building models of listening performance that incorporate a wide range of overlapping difficulty components and exploring their effects on performance.

There is a need for teachers, curriculum designers and language testers to determine whether changes in task characteristics and task conditions in competency based listening tasks would result in differences in test performance (Brindley, 2002). Knowing which variables were likely to affect test scores provide a basis for controlling task difficulty and thus for making tasks more comparable in the interests of fairness. However, the complexities of the interactions between task characteristics, item characteristics and candidate responses suggest that adjusting one will not make the task either easier or more difficult.

\section{REFERENCES}

[1] Brindely, G. (2002). Exploring task difficulty in ESL listening assessment. Language Testing 10 (1)

[2] Brindley, G. \& Slatyer. H. (2002). Exploring task difficulty in ESL listening assessment, Language Testing 19 (4) $369-394$.

[3] Brown, J.D. (1986). The effectiveness of teaching reduced form of listening comprehension. RELC Journal 12(1).

[4] Brown, J. \& Hilferty. (986). The Effectiveness of Teaching Reduced Forms of Listening comprehension, RELC Journal 17-59.

[5] Collentine, J., \& Freed, B. (2004). Learning Context and its Effects on Second Language Acquisition. Studies in Second Language Acquisition 26, 153-171.

[6] Díaz-Campos, M. (2004). Context of Learning in the Acquisition of Spanish Second Language Phonology. Studies in Second Language Acquisition 26, 249-273.

[7] Elder, C., McNamara, T. \& Iwashita, N. (2002). Estimating the difficulty of oral proficiency tasks: what does the test-taker have to offer? Language Testing 19 (4) 347-368.

[8] Ellis, R. (1994). Second Language Acquisition. Oxford: Oxford University Press.

[9] Foster, P. and Skehan, P. (1996). The influence of planning and task type on second language performance. Studies in Second Language Acquisition 18, 299-323.

[10] Gass, S. (2002). Frequency effects and second language acquisition. Studies in Second Language Acquisition 6. 
[11] Gass, S. \& Mackey, A. (2002). Frequency Effects and Second Language Acquisition: A Complex Picture? Studies in Second Language Acquisition 24, 249-260.

[12] Iwashita, N., McNamara, T. and Elder, C. (2001). Can we predict task difficulty in a proficiency test? Exploring the potential of an information processing approach to task design. Language Learning 21, 401-36.

[13] Leeser, M. (2004). The Effect of topic familiarity, mode, and pausing on second language learners' comprehension and focus on form. Studies in Second language Acquisition 26, 587-615.

[14] Skehan, P. (1996). A framework for the implementation of task-based instruction. Applied Linguistics 17, 38-62.

[15] Skehan, P. and Foster, P. (1999). The influence of task structure and processing conditions on narrative retellings. Language Learning 49, 93-120.

[16] Robinson, P. (1995). Task complexity and second language narrative discourse. Language Learning 45, 141-75.

[17] Robinson, P. (2001).Task complexity, task difficulty and task production: Exploring interactions in a componential framework. Applied Linguistics 21, 27-57.

[18] Uso'-Juan \& Martı'nez-Florn. (2006). Current Trends in the Development and Teaching of the four Language Skills. Mouton de Gruyter Berlin. New York

Zohre Mohamadi is a PhD candidate at Tarbiz University in teaching English as a foreign language. She accomplished her MA degree at Iran University of Science and Technology and her BA at Islamic Azad University. She has been the top student and top graduate student in all her educational programs.

She has published many papers in related journals and attended international conferences. She organized and presented different workshops on second language acquisition and learning. Her research interests are teacher education and training, materials development and teaching SPSS for research purposes. She teaches to both graduate and post graduate students.

Ms. Mohamadi is a faculty member of English teaching department at Islamic Azad University of Karaj, Karaj, Iran. She is also a member of TELLSI (Teaching English Language and Literature Society of Iran). She has been a referee at Islamic Azad University conferences. 